\title{
polymers
}

ISSN 2073-4360

www.mdpi.com/journal/polymers

Article

\section{Synthesis of Polypyrrole-Intercalated Grafted Zirconium Phosphate Films by Anodic Electrodeposition and Their Electrochemical Capacities}

\section{Takahiro Takei *, Qiang Dong, Yoshinori Yonesaki, Nobuhiro Kumada and Nobukazu Kinomura}

Center for Crystal Science and Technology, University of Yamanashi, 7-32 Miyamae, Kofu, Yamanashi 400-8511, Japan; E-Mails: dongqiang@ yamanashi.ac.jp (Q.D.); yonesaki@yamanashi.ac.jp (Y.Y.); kumada@yamanashi.ac.jp (N.K.); kinomura@yamanashi.ac.jp (N.K.)

* Author to whom correspondence should be addressed; E-Mail: takei@yamanashi.ac.jp; Tel.: +81-55-220-8616; Fax: +81-55-254-3035.

Received: 4 November 2010; in revised form: 30 November 2010 / Accepted: 20 December 2010 / Published: 23 December 2010

\begin{abstract}
Ternary hybrid film composed of $\alpha$-zirconium phosphate nanosheet, 1,2-bis(dimethylchlorosilyl)ethane and polypyrrole was prepared by anodic electrodeposition. In the hybrid film, ordered $\alpha$-zirconium nanosheets with grafts by silylation lay down parallel to the substrate and the polypyrrole molecules were intercalated between the nanosheets. The electrochemical measurements confirmed that the hybrid film indicated capacitive behavior and the redox activity increase by approximately $25 \%$.
\end{abstract}

Keywords: electrodeposition; electrochemical capacitor; graft; polypyrrole; zirconium phosphate

\section{Introduction}

The conductive polymers, e.g., polyaniline, polypyrrole and polythiophene, have been examined for electric charging devices, radar absorbing material, actuators, etc. In particular, the polymer should have a redoxable activity for application on the electrode of the charging devices. Generally, 
polyaniline and polypyrrole show multi-step redox reactions at relatively wide range potential. Therefore, polyaniline and polypyrrole have been examined for electrochemical capacitor or secondary battery use by many researchers [1-5]. In order to accelerate or improve their properties, inorganic-conductive polymer hybrids, which are nanoparticle-dispersed structures and/or conductive polymer-intercalated layered compounds, were examined as follows. Schnitzler, et al. reported preparation of a $\mathrm{TiO}_{2}$ nanoparticle/polyaniline hybrid [6]. Manganese oxide/polypyrrole nanocomposites were studied by Sharma et al. [7]. Vanadium oxide and polypyrrole nanocomposite aerogel was examined by Wong et al. [8]. For intercalation of conductive polymer, Kerr et al. reported polyaniline-intercalated molybdenum oxide [9]. Wang et al. reported layered manganese oxide with intercalation of polyaniline [10]. For such intercalated compounds, since the conductive polymer is dispersed at the molecular level, the ratio of the reacted polymer tends to increase. Especially when redoxable inorganic material is the host, the redox reactions sometimes enhanced each other. In these hybrids, aniline or pyrrole was polymerized within the interlayer space by oxidant or by heat. Therefore, obtained products had a powder state. On the other hand, Takei et al. reported preparation of oriented metal phosphate and polyaniline hybrid film by electrolytic and electrophoretic simultaneous depositions [11,12]. In this process, layered material was at first exfoliated to form nanosheets, and electrophoretically deposited together with electrolytic polymerization of aniline. This electrodeposition has a large advantage in such formation of hybrid film; however, such hybrid film did not show good redox activity because the ion diffusing paths are not enough for quick redox reactions. To increase the diffusion path, metal nanosheets grafted with organic chain were used instead of the metal phosphate nanosheets. Previously, Takei reported that the grafting provided a large increase in redox activity (around 1.7-times) for polyaniline-including film [13]. In this paper, we prepare polypyrrole (PPy) and nanosheet hybrid film, instead of the polyaniline, and examine redox behavior.

\section{Results and Discussion}

\subsection{Structure of the Grafted Zirconium Phosphate and Polypyrrole Hybrid Films}

The grown films from the grafted nanosheet solution are designated as ' $\mathrm{gr}-\mathrm{ZrP} / k$ ' hereafter, where $k$ means the loaded ratio of silane molecules to $\alpha-\mathrm{ZrP}$. When the solution includes the pyrrole monomer, '+PPy' is added on the back of the sample's name. Figure 1 shows the XRD patterns of the grown films without PPy. The patterns of $\alpha-\mathrm{ZrP}$ indicate that the film is composed of non-grafted nanosheets. Only one diffraction peak is shown at around $0.78 \mathrm{~nm}$, corresponding to the interlayer spacing of the $\alpha-Z r P$. Since no other peaks are shown in the patterns, $\alpha-Z r P$ seems to be exfoliated. The others denote the patterns of the samples prepared from the grafted nanosheet with various amounts of graft loaded. Actual amounts of graft molecules per $\alpha$-zirconium phosphate are $0.05,0.21$ and 0.44 for gr-ZrP/0.5, 2.0 and 3.0, respectively. These patterns confirm that the new diffraction peak emerges at approximately $1.4 \mathrm{~nm}$ in interlayer spacing, which derives from the expanded interlayer space by graft molecules. Within the interlayer, the grafts possibly exist as a bilayer.

Figure 2 shows the XRD patterns of the grown hybrid films with PPy. From the bottom pattern of $\alpha-\mathrm{ZrP}+\mathrm{PPy}$, the diffraction peak becomes much broader than that of the sample without PPy. The peak is apparently composed of two peaks with around $0.8 \mathrm{~nm}$ and $1.1 \mathrm{~nm}$ in d-spacing. The peak at $0.8 \mathrm{~nm}$ probably corresponds to the phase which does not include PPy within the interlayer space. 
On the other hand, the peak at around $1.1 \mathrm{~nm}$ is attributed to PPy-intercalated phase. The other patterns of the films composed of the grafted nanosheet and PPy demonstrate that broad peaks emerged at almost same degree with that of the film without PPy. Such almost identical d-spacing does not mean no PPy intercalated because the graft probably acted as a pillar.

Figure 1. XRD patterns of the grown films from the solution containing the exfoliated nanosheet of (a) $\alpha-\mathrm{ZrP}$, (b) gr-ZrP/0.5, (c) gr-ZrP/2.0 and (d) gr-ZrP/3.0.

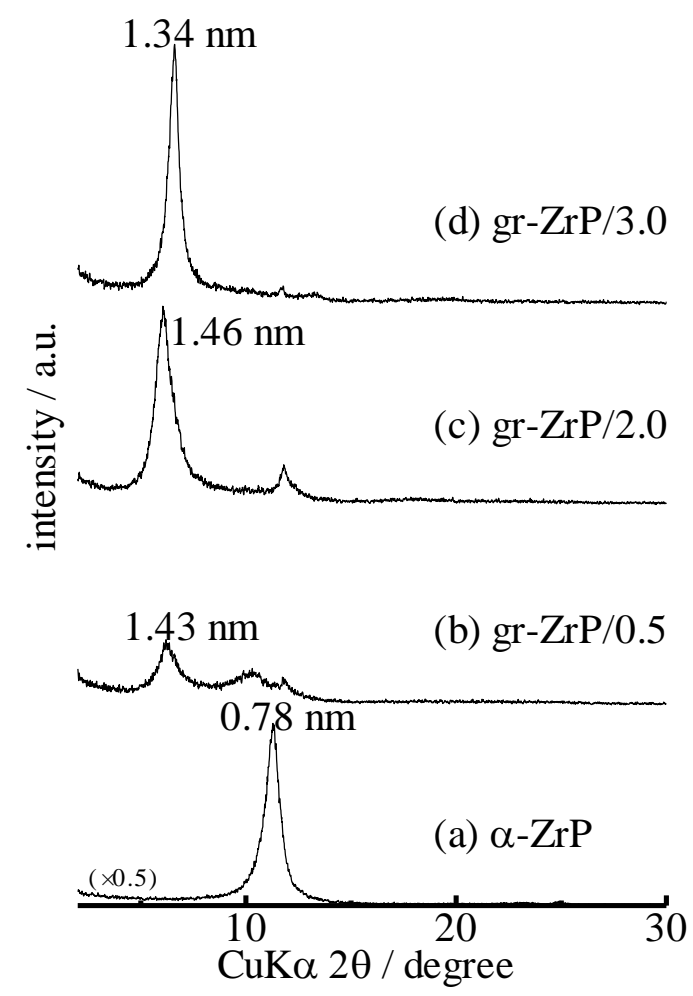

Figure 2. XRD patterns of the grown films from the solution containing the exfoliated nanosheet of (a) $\alpha-\mathrm{ZrP}$, (b) gr-ZrP/0.5, (c) gr-ZrP/2.0, (d) gr-ZrP/3.0; and pyrrole monomer.
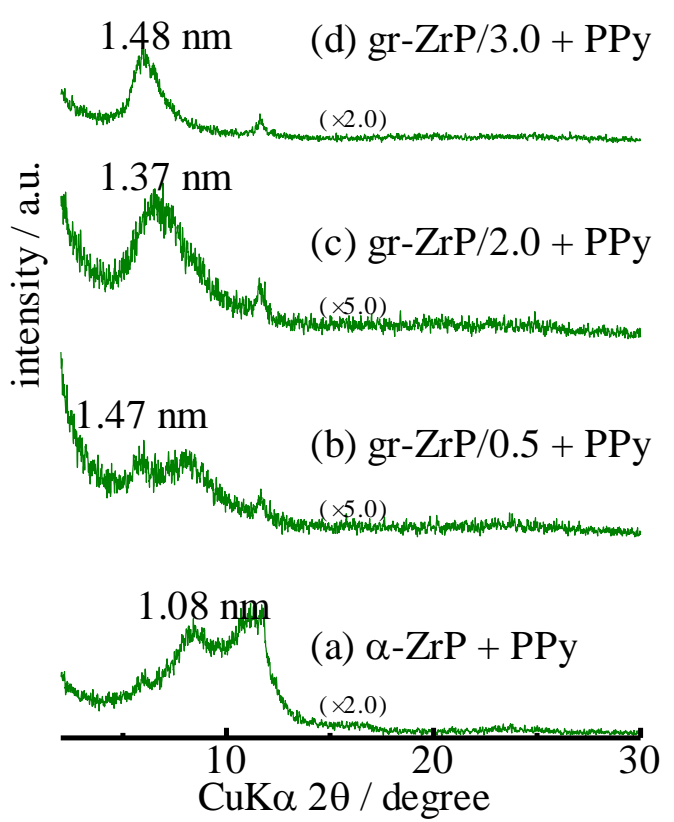
The general formula of the ' $\mathrm{gr}-\mathrm{ZrP} / k+\mathrm{PPy}^{\prime}$ is declared as ' $\mathrm{ZrP}$ (silane) $)_{n}$ (PPy)', where $l$ means the amount of PPy per pyrrole unit. Figure 3 shows amount of the grafted silane in the nanosheet and PPy hybrid versus the amount of PPy in the film. The amount of PPy steeply increased by three-times when using the gr-ZrP nanosheet. This increase of PPy seems to be collateral evidence for the existence of a large amount of PPy within the interlayer space. At larger than around 0.1 of $n, l$ was prone to decrease gradually due to an increase of pillar density.

Figure 3. Relationship between the amount of silane molecules present in the samples and the amount of PPy included.

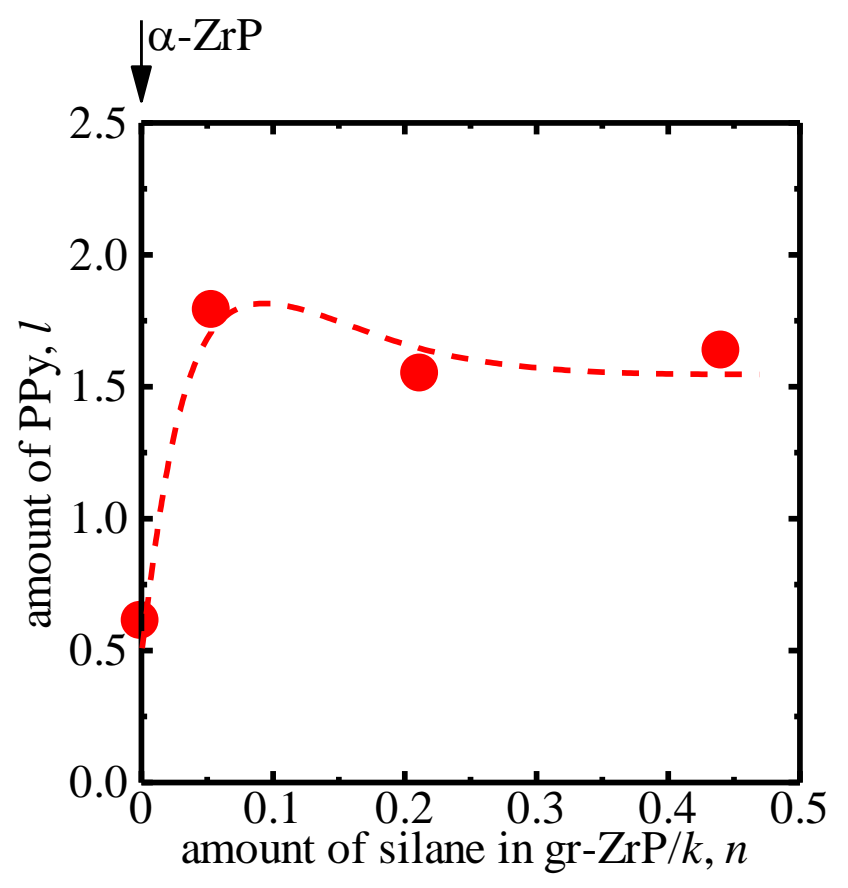

\subsection{FT-IR Study on the Grafted ZrP and PPy Hybrid Films}

Figure 4 shows the ATR (Attenuated Total Reflection) spectra of FT-IR for the grown film from $\alpha-\mathrm{ZrP}, \mathrm{gr}-\mathrm{ZrP} / k$ and gr-ZrP/ $k+\mathrm{PPy}$ hybrid. For the $\alpha-\mathrm{ZrP}$ film, there is some absorption of $v\left(\mathrm{H}_{2} \mathrm{O}\right)$ at 3,517 and 3,594 $\mathrm{cm}^{-1}$ and $v(\mathrm{OH})$ at $3,145 \mathrm{~cm}^{-1}$ and many cases of absorption of the $\mathrm{P}-\mathrm{O}$ bond are shown within the fingerprint region. For gr- $\mathrm{ZrP} / k$ film, absorption of $v\left(\mathrm{H}_{2} \mathrm{O}\right)$ and $v(\mathrm{OH})$ vanished because the $\mathrm{OH}$ group was used for the silylation reaction. New absorption emerged at $800 \mathrm{~cm}^{-1}$, which can be attributed to $v(\mathrm{Si}-\mathrm{C})$. This absorption is one piece of evidence for silylation. For gr-ZrP/ $k+$ PPy hybrid film, broad $v(\mathrm{~N}-\mathrm{H})$ absorption was particularly apparent at around 3,500 $\mathrm{cm}^{-1}$. In addition, absorption at $1,567 \mathrm{~cm}^{-1}$ also emerged. This absorption is possibly attributed to $v(\mathrm{C}=\mathrm{C})$. These two absorptions, at 3,500 and 1,567 $\mathrm{cm}^{-1}$, can be regarded as evidence of PPy existence [14]. In this spectrum, $v(\mathrm{Si}-\mathrm{C})$ absorption was apparently diminished. This decrease may reflect interaction between the graft molecule and PPy. That is, these spectra confirm that PPy was intercalated between grafted nanosheets in the hybrid film. However, 1,2-bis(dimethylchlorosilyl) ethane did not react chemically with polypyrrole.

Figure 5 shows a schematic illustration of the gr-ZrP/ $k+$ PPy. The hybrid films were composed of $\alpha-\mathrm{ZrP}$ nanosheets, PPy and organic silane which propped the $\mathrm{ZrP}$ nanosheets. The propped structure 
provides expansion of the interlayer space. Therefore, larger amounts of PPy can be intercalated within the interlayer spacing than that of $\alpha-\mathrm{ZrP}$ film, as shown in Figure 3.

Figure 4. FT-IR/ATR spectra of the grown film. (a) $\alpha-\mathrm{ZrP}$, (b) gr-ZrP/2.0 and (c) $\mathrm{gr}-\mathrm{ZrP} / 2.0+\mathrm{PPy}$.

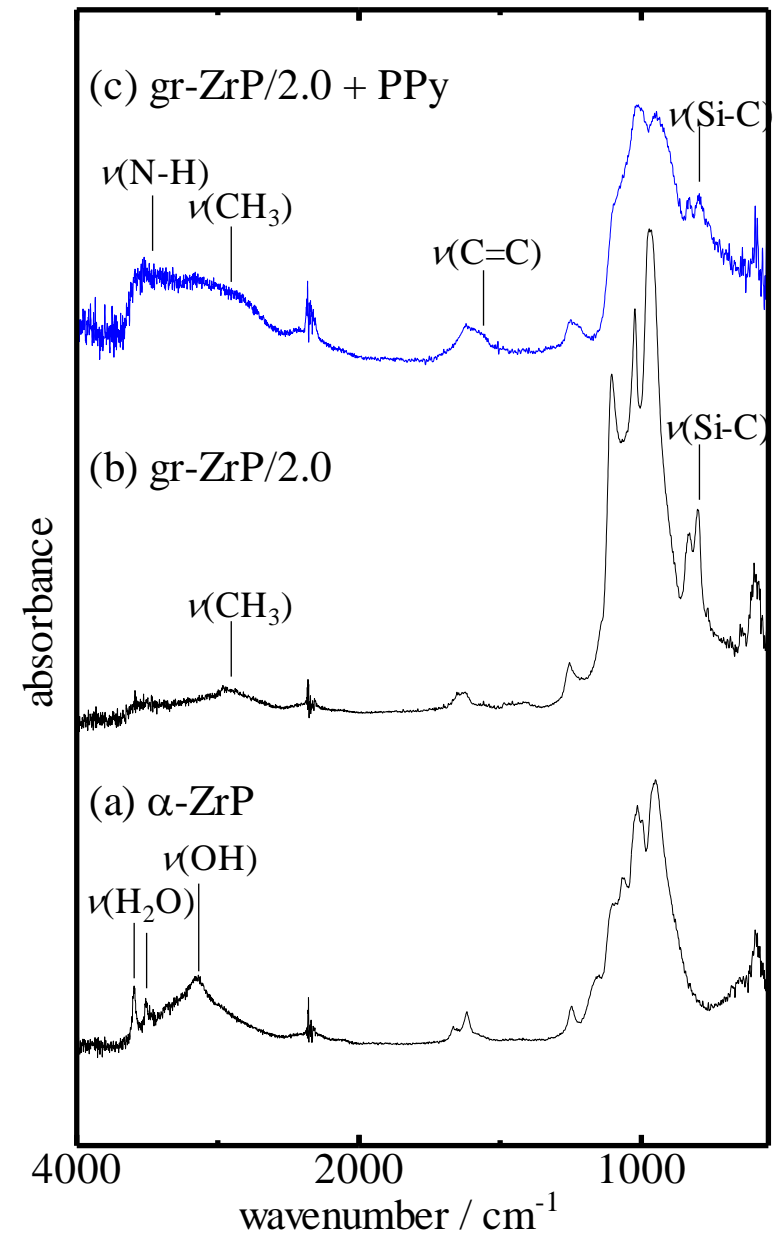

Figure 5. Schematic illustrations of the hybrid film, gr-ZrP/ $\underline{k}+\mathrm{PPy}$.

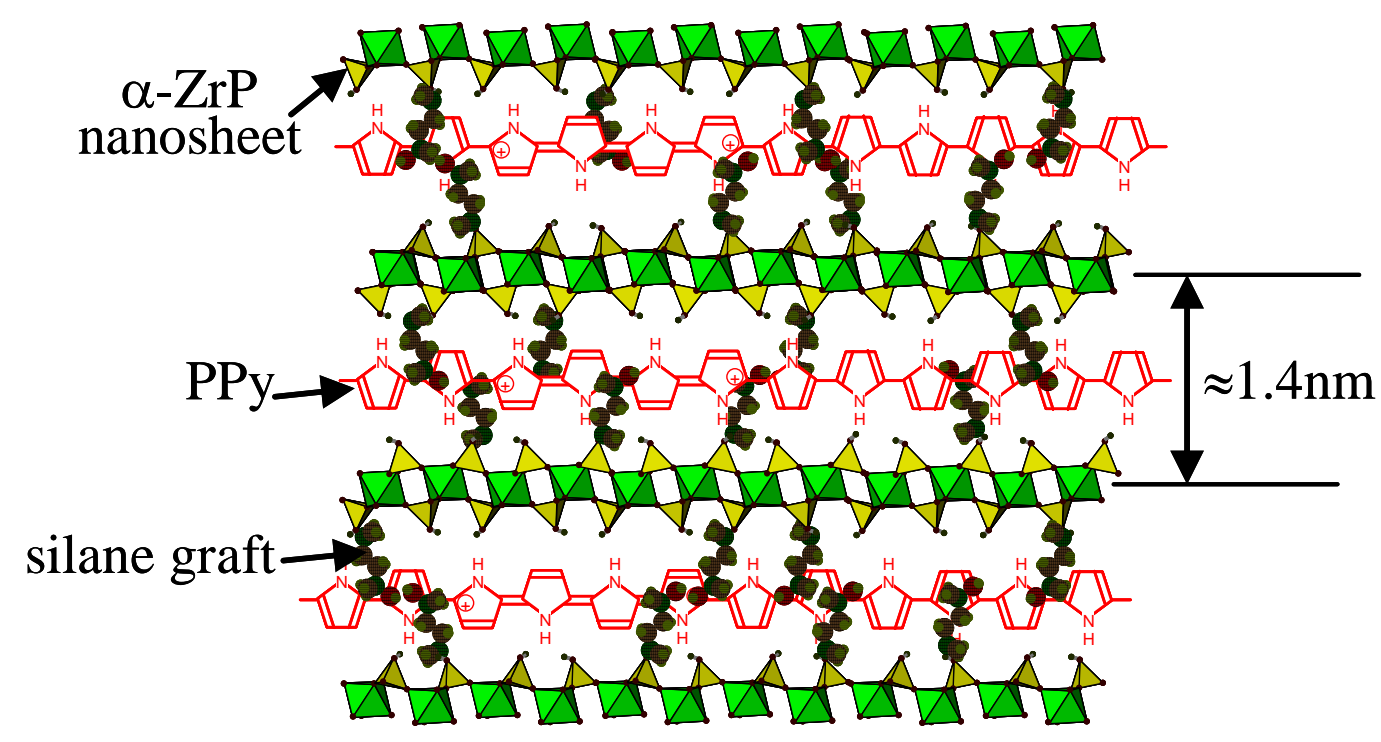




\subsection{Electrochemical Properties}

Figure 6 shows the cyclic voltammograms of the grown PPy hybrid films from the solution including $\alpha-\mathrm{ZrP}, \mathrm{gr}-\mathrm{ZrP} / k$ and pyrrole. The area of the voltammogram loop apparently increased by using $\mathrm{gr}-\mathrm{ZrP} / k$. Especially for gr-ZrP/0.5, the loop area maximized within this condition. The current of the voltammograms may indicate adsorption and desorption of $\mathrm{ClO}_{4}{ }^{-}$anions because a great extent of the sweep range is positive; however, specific redox peak is not observed. Figure 7 shows the galvanostatic charge-discharge curves for these hybrid films. These curves seem to show capacitive behavior. Therefore, such charge-discharge curves denote capability for the application of an electrochemical capacitor.

Figure 8 shows the dependence of gravimetric capacitance per PPy on the actual amount of grafts. From this plot, the gravimetric capacitance maximized at 0.07 to achieve around $110 \mathrm{~F} / \mathrm{g}$, and then gradually decreased. The capacitance increased around 1.3 times to that of $\alpha-\mathrm{ZrP}+\mathrm{PPy}$ hybrid (non-grafted); however, it seems to be not a large advantage for the grafts. Such a trend may be due to a too high amount of PPy within the interlayer space. An excess amount of PPy may prevent ion diffusion. In addition, this capacitance is not large compared with the values of several hundred F/g that was reported by some literatures [4,7]. However, high order structured film prepared in our present research is much interesting for applications in electrochemical devices, sensor or adsorbent. At least for the application of the electrochemical capacitor, improvement of the structure may be necessary.

Figure 6. Cyclic voltammograms of the grown film (sweep rate: $20 \mathrm{mV} / \mathrm{sec}$ ). (a) $\alpha-\mathrm{ZrP}+\mathrm{PPy},(\mathbf{b})$ gr-ZrP/0.5 + PPy, (c) gr-ZrP/2.0 + PPy and (d) gr-ZrP/3.0 + PPy.

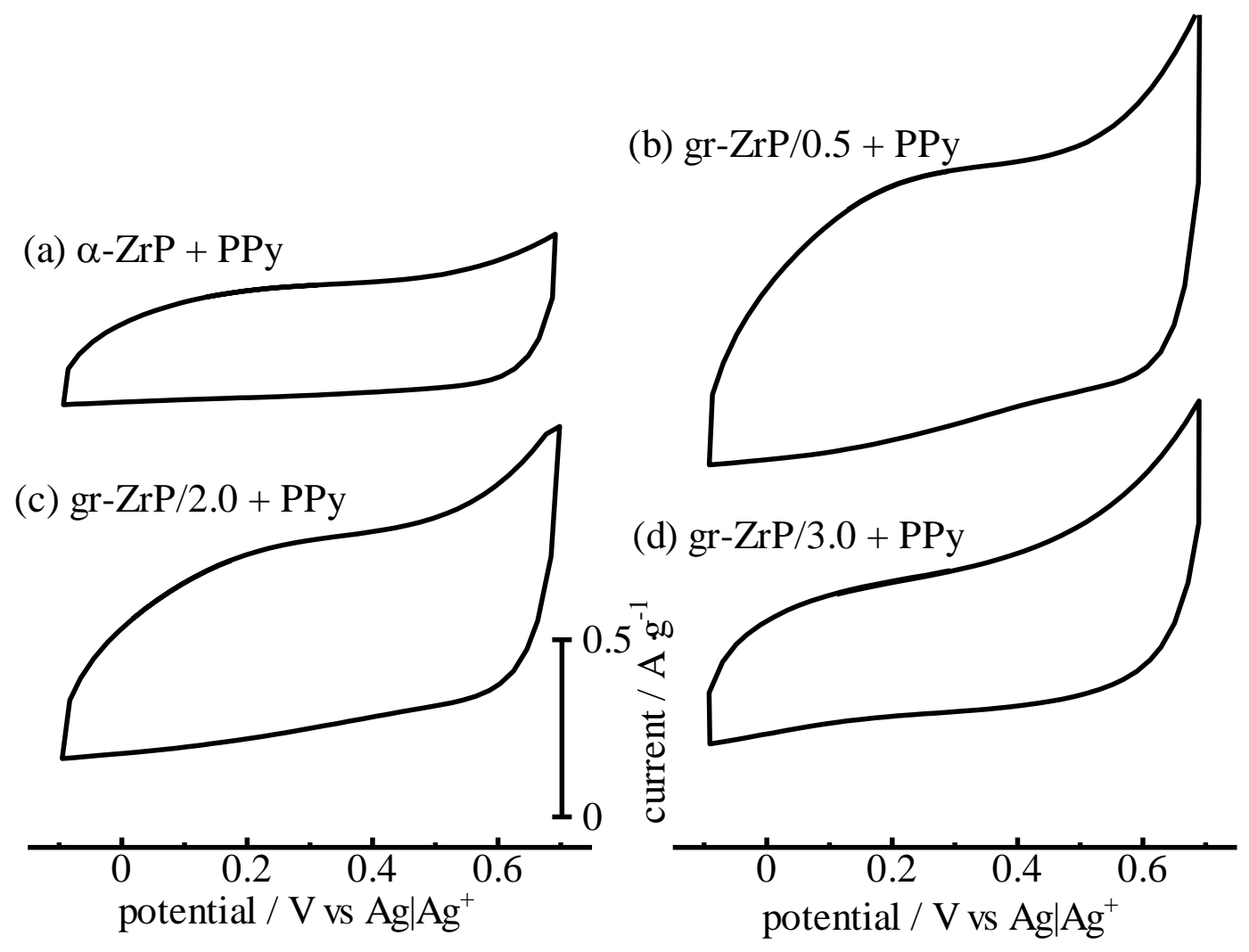


Figure 7. Galvanostatic charge-discharge curves of the grown film (current: $\pm 100 \mu \mathrm{A}$ ). (a) $\alpha-\mathrm{ZrP}+\mathrm{PPy}$, (b) gr-ZrP/0.5 + PPy, (c) gr-ZrP/2.0 + PPy; and (d) gr-ZrP/3.0 + PPy.

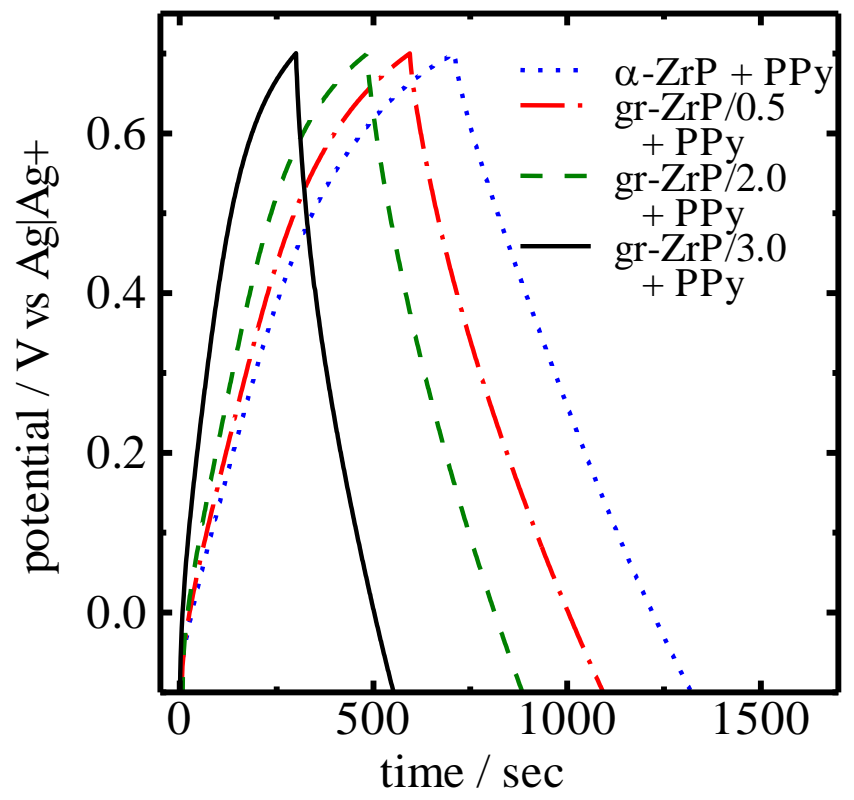

Figure 8. Relationships between the amount of silane molecules present in the samples and the gravimetric capacitance per PPy in the sample.

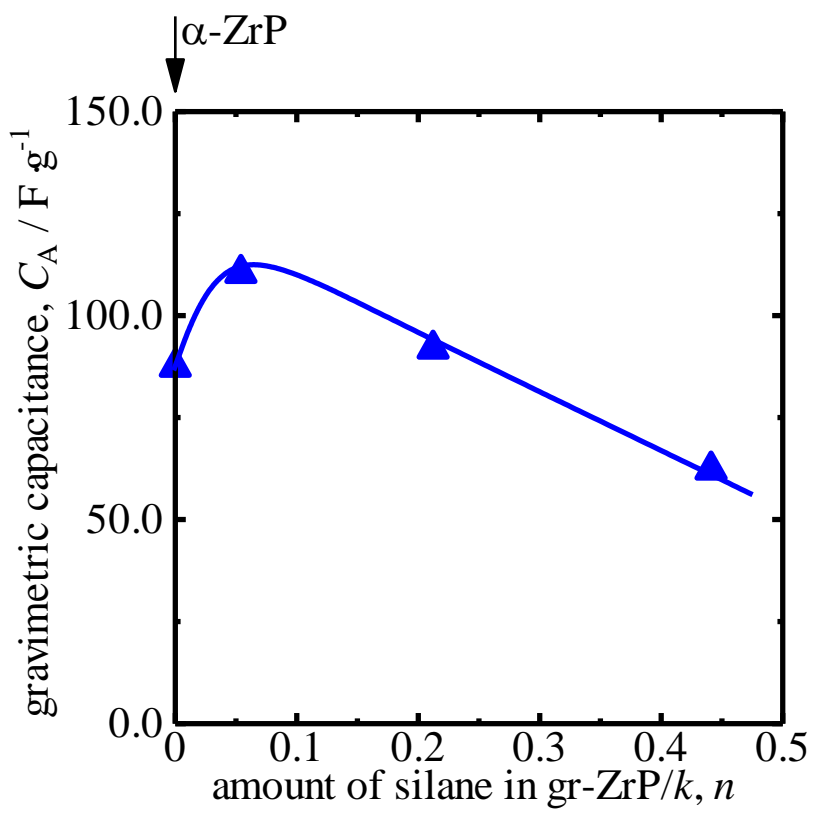

\section{Experimental Section}

Zirconium phosphate was used for the inorganic nanosheet. In this study, the nanosheets were chemically modified by silylation reaction as reported [15]. The modification was developed by reaction of hydroxyl groups and chlorine in the organic silane. The typical process is as follows. The $\alpha$-zirconium phosphate was at first intercalated by octylamine molecules to expand interlayer spaces and then was silylated by 1,2-bis(dimethylchlorosilyl) ethane. The zirconium phosphate was put 
into $20 \%$ octylamine ethanolic solution and was shaken for $168 \mathrm{~h}$. Then, the intercalated zirconium phosphate obtained by such a process was put into toluene with organic silane. To combine zirconium phosphate nanosheets with organic silane in a chemical reaction, the solution was refluxed at $70{ }^{\circ} \mathrm{C}$ for $48 \mathrm{~h}$. The sample was washed in toluene and water, and stirred in dilute $\mathrm{HCl}$ aqueous solution to remove unwanted octylamine-related compounds.

The silylated zirconium nanosheet was exfoliated in $4.96 \mathrm{mmol} / \mathrm{L}$ tetrabutylammonium hydroxide $(\mathrm{TBAOH})$ and chloride (TBACl) acetonitrile solution by stirring for 1 week. Then, pyrrole as a monomer of polymer was put into the solution with the concentration of $20 \mathrm{mmol} / \mathrm{L}$. Using this solution, electrodeposition was carried out as follows. Platinum plates $(50 \mathrm{~mm} \times 10 \mathrm{~mm} \times 0.1 \mathrm{~mm})$ were immersed with depth of $20 \mathrm{~mm}$ and were used for electrode of the anodic electrodeposition with separation of $10 \mathrm{~mm}$. The film was deposited by DC power source (Yokogawa electric, 7651) with a constant current of $1.25 \mathrm{~mA} / \mathrm{cm}^{2}$ for $15 \mathrm{~min}$, at which the hybrid film was obtained. After the deposition, the sample was dried at room temperature.

The texture of the obtained film was examined by XRD (Rigaku, RINT-2000) and FT-IR (Jasco, FT/IR4100) using an ATR (Attenuated Total Reflection) attachment with ZnSe lens. The electrochemical property was examined by cyclic voltammogram and galvanostatic charge-discharge measurement in 3-electrode cell using potentiostat/galvanostat (Hokuto denko, HAL-2001), function generator (Hokuto denko, HB-301) and digital multimeter (ADCMT, 7352A) in $1 \mathrm{M} \mathrm{NaClO}_{4}$ acetonitrile solution. The sweep range was set from -0.1 to $+0.7 \mathrm{~V}$ versus $\mathrm{Ag} \mid \mathrm{Ag}^{+}$. Composition and the amount of polypyrrole in the film were measured by ICP (Hitachi, P4010) and CHN (Yanaco, MT-5) elementary analyses.

\section{Conclusions}

The redox hybrid film composed of $\mathrm{ZrP}$ nanosheet, 1,2-bis(dimethylchlorosilyl) ethane and polypyrrole formed in the solution including silane-grafted $\mathrm{ZrP}$ nanosheet colloids and pyrrole molecules. The FT-IR spectra and XRD patterns confirm that polypyrrole was probably intercalated with the interlayer space. Thus, the grown hybrid film has a structure with an ordered nanosheet that is propped by the grafts and polypyrrole. The ratio of actual contained polypyrrole to silane-grafted $\mathrm{ZrP}$ in the film was around 1.5, whereas that propped structure was found to achieve an increase of redox activity by around $25 \%$.

\section{References}

1. Hu, C.C.; Chu, C.H. Electrochemical and Textural Characterization of Iridium-Doped Polyaniline Films for Electrochemical Capacitors. Mater. Chem. Phys. 2000, 65, 329-338.

2. Varela, H.; Maranhão, S.L.A.; Mello, R.M.Q.; Ticianelli, E.A.; Torresi, R.M. Comparisons of Charge Compensation Process in Aqueous MEDIA of Polyaniline and Self-Doped Polyanilines. Synthet. Metal. 2001, 122, 321-327.

3. Hu, C.C.; Chen, E.; Lin, J.Y. Capacitive and Textural Characteristics of Polyaniline-Platinum Composite Films. Electrochim. Acta 2002, 47, 2741-2749. 
4. Khomenko, V.; Frackowiak, E.; Béguin, F. Determination of the Specific Capacitance of Conducting Polymer/Nanotubes Composite Electrodes Using Different Cell Configurations. Electrochim. Acta 2005, 50, 2499-2506.

5. Huang, J.E.; Li, X.H.; Xu, J.C.; Li, H.L. Well-Dispersed Single-Walled Carbon Nanotube/Polyaniline Composite Films. Carbon 2003, 41, 2731-2736.

6. Schnitzler, D.C.; Zarbin, A.J.G. Organic/Inorganic Hybrid Materials Formed from $\mathrm{Tio}_{2}$ Nanoparticles and Polyaniline. J. Brazil Chem. Soc. 2004, 15, 378-384.

7. Sharma, R.K.; Rastogi1, A.C.; Desu, S.B. Manganese Oxide Embedded Polypyrrole Nanocomposites for Electrochemical Supercapacitor. Electrochim. Acta 2008, 53, 7690-7695.

8. Wong, H.P.; Dave, B.C.; Leroux, F.; Harreld, J.; Dunn, B.; Nazar, L.F. Synthesis and Characterization of Polypyrrole/Vanadium Pentoxide Nanocomposite Aerogels. J. Mater. Chem. 1998, 8, 1019-1027.

9. Kerr, T.A.; Wu, H.; Nazar, L.F. Concurrent Polymerization and Insertion of Aniline in Molybdenum Trioxide: Formation and Properties of a $[\mathrm{Poly}(\text { aniline })]_{0.24} \mathrm{MoO}_{3}$ Nanocomposite. Chem. Mater. 1996, 8, 2005-2015.

10. Wang, Y.G.; Wu, W.; Cheng, L.; He, P.; Wang, C.X.; Xia, Y.Y. A Polyaniline-Intercalated Layered Manganese Oxide Nanocomposite Prepared by an Inorganic/Organic Interface Reaction and Its High Electrochemical Performance for Li Storage. Adv. Mater. 2008, 20, 2166-2170.

11. Takei, T.; Yonesaki, Y.; Kumada, N.; Kinomura, N. Preparation of Oriented Titanium Phosphate and Tin Phosphate/Polyaniline Hybrid Films by Electrochemical Deposition. Langmuir 2008, 24, 8554-8560.

12. Takei, T.; Kobayashi, Y.; Hata, H.; Yonesaki, Y.; Kumada, N.; Kinomura, N.; Mallouk, T.E. Anodic Electrodeposition of Highly Oriented Zirconium Phosphate and Polyaniline-Intercalated Zirconium Phosphate Films. J. Am. Chem. Soc. 2006, 128, 16634-16640.

13. Takei, T.; Yonesaki, Y.; Kumada, N.; Kinomura, N. Effect of Organosilane-Grafting to Layered Zirconium Phosphate on Redox Behavior for Electrodeposited Zirconium Phosphate/Polyaniline Hybrid Film. In Abstracts of Joint Conference of STAC2 and STSI1; Proceedings of STAC-STAI, Chiba, Japan, May 2008; p. 74.

14. Jin, J.L.; Ando, T.; Teramae, N.; Haraguchi, H. Characterization of Electropolymerized Polypyrrole Films by FT-IR Reflection Absorption Spectroscopy. Jpn. Soc. Anal. Chem. 1991, 40, 799-804.

15. Takei, T. Kumada, N.; Kinomura, N.; Nakayama, H.; Tsuhako, M. Preparation of Silylated Alpha-Zirconium Phosphate and Its Thermal Behavior. Mater. Res. Bull. 2008, 43, 111-119.

(C) 2010 by the authors; licensee MDPI, Basel, Switzerland. This article is an open access article distributed under the terms and conditions of the Creative Commons Attribution license (http://creativecommons.org/licenses/by/3.0/). 